\title{
BIBLIOGRAFIA
}

\section{Ensayo Bibliográfico de los Catálogos de Sujetos de la Compañía de Jesús en Nueva España}

\author{
INTRODUCCION
}

TVESTIGANDO sobre el rico fondo de documentos de la Compañía de Jesús en la Nueva España que posee nuestro Archivo General de la Nación, he dado con un buen número de catálogos de sujetos de la Provincia de México, parte de los cuales se hallan encuadernados y reunidos en el tomo 309, del Ramo de Historia, Sección Jesuítas. Los demás han sido encontrados en diversos lugares, en acervos en vías de catalogación, y vienen a completar el grupo de los catálogos manuscritos, junto con los ocho ejemplares que se conservan en la Sección de Manuscritos de la Biblioteca Nacional de México y cuyo conocimiento debo a mi muty ąpreciable amigo el señor don Juan B. Iguíniz. ${ }^{1}$ Por lo que se refiere a los impresos, las fichas han sido tomadas de las obras mencionadas al calce de cada una de ellas. En esta forma he podido reunir una colección de 78 catálogos, materia del presente ensayo bibliográfico.

Su finalidad tiende a dar a conocer y divulgar la suma importancia que para el conocimiento de la historia de nuestros jesuítas presentan, ya que constituyen por sí solos una fuente inapreciable, y a veces única, de noticias sobre diversas materias, tanto estadísticas y económicas, como biográficas.

E1 uso de los Catálogos de Sujetos de la Compañia de Jesús es muy antiguo y casi coetáneo a la fundación del instituto de San 
Ignacio de Loyola. Así nos lo hace saber el P. Astráin en su admirable Historia de la Compañía de Jesús en la antigua Asistencia española, quien, en el t. I, pág. 409, dice que el primer catálogo fué formado durante la visita del P. Nadal a la Provincia de la madre patria, y que abarca, al parecer, los años de 1550-1553.

En la Provincia de México sabemos existieron catálogos de 1575 y de 1585 , que desgraciadamente no hemos podido haber a las manos. Tenemos conocimiento también, según nos lo ha comunicado nuestro apreciable amigo el sabio historiador don Federico Gómez de Orozco, de que en el Archivo General de la Nación existió una lista, formada al expirar el siglo xvi, de todos los sujetos que ejercieron sus ministerios en la Nueva España desde su llegada en 1572 hasta aquella fecha, que no hemos podido encontrar, y cuya falta ha hecho laborioso nuestro Apéndice, que tiene la pretensión de ser un catálogo de los jesuítas en sus primeros veintiocho años de trabajos en nuestra patria.

El catálogo más antiguo que conocemos, y que encabeza nuestro ensayo, está fechado en 1674. Es el Tercero, o sea el de las Cosas de la Provincia, y su existencia revela, cuando menos, la de los Primero, Segundo y Cuarto que le son complementarios. Con el de 1696, son los únicos del siglo xvIr que se consignan. De la siguiente centuria podemos decir, afortunadamente, que contamos con los que la abarcan por completo, descle 1708 hasta 1767 , formado este último por el P. Zelis y ampliado por el P. Márquez años después, y que fué publicado en esta ciudad en 1871. Hemos incluído también, y con él termina la colección, el de 1820 , por hallarse publicado todavía durante la dominación española, aunque en verdad nuestro propósito debe más bien referirse a la época comprendida entre 1572, fecha del establecimiento de la Compañia en México, hasta 1767, año que señala su primera expulsión.

La mayor parte de los catálogos consignados son manuscritos. No sé si todos salieron a la prensa, aunque me inclino a pensar que no, pues no tendría objeto publicarlos tan seguidamente como se formaban. Sin embargo, conocemos los catálogos impresos en 1751, 1758 y 1764.

Los catálogos se formaban, de acuerdo con instrucciones concretas de los PP. Generales, siguiendo cuatro diversos tipos o modelos, complementarios entre sí. En el Primero se hacían constar: a) Nomen et Cognomen (nombre y apellido); b) Patria; c) AEtas 
(edad); d) Vires (constitución física); e) Tempus societatis (tiempo de sociedad) ; f) Tempus studiorum (tiempo de estudios); g) Tempus ministeriorum (tiempo de ministerios); h) Gradus in litteris (grado en letras); i) Gradus in societate (grado en la sociedad). En el Segundo: a) Ingenium; b) Judicium; c) Prudentia; d) Experientia; e) Profectus in litteris (aprovechamiento en letras) ; f) Complexio (lo que actualmente se llama temperamento); g) Talentum. El Catálogo Tercero se ocupaba de presentar el estado de las cosas de la Provincia, o sean las casas, colegios, residencias, misiones, etc., y revela datos de carácter estadístico y económico. Por último, el Cuarto contiene la relación de las personas en función de los cargos que desempeñaban en las cosas a que se refiere el tercero.

En esta forma puede considerarse que una serie completa de los cuatro catálogos de una época determinada constituía un cuadro resumido, pero exacto y valioso, del estado en que se hallaba la provincia mexicana. Pondremos un ejemplo: ${ }^{2}$

En el catálogo manuscrito del primero de julio de 1748, formado por el P. Provincial Andrés Xavier García, aparece el P. Juan Antonio de Oviedo, bajo el número 9, siendo sus características las siguientes: Nombre y apellido, los ya dichos; Patria, Santa Fe de Bogotá; Edad, 78 años; Constitución física, buena; Tiempo de Sociedad, 58 años; Tiempo de estudios, absuelto; Tiempo de ministerios, enseñó Retórica, Filosofía y Teología; fué Socio Provincial; Visitador General de la Provincia de Filipinas; Procurador en Roma; Rector; Provincial en otro tiempo, y actualmente Prepósito de la Casa Profesa; Grado en letras, Doctor en Teología ; Grado en la Sociedad, Profeso de 4 votos desde el año de 1704.-Todos estos datos obran en el Catálogo Primero.

En el Catálogo Segundo: Ingenio, óptimo; Juicio, óptimo; Prudencia, grande; Experiencia, mucha; Aprovechamiento en letras, óptimo; Temperamento, moderado; Talento, para todas las cosas.

En el Catálogo Tercero, buscando en lo referente a la Casa Profesa, de la que era Prepósito en ese tiempo nuestro Oviedo, encontramos: Otros 28 de los nuestros, de los cuales 15 son sacerdotes, el primero de ellos es el Prepósito de la Casa (Profesa), y su primer ministro; 2 Prefectos de las Congregaciones, el primera de los cuales es Prefecto de la Doctrina Cristiana; de los restantes, 13 son Coadjutores, de los que 3 son limosneros; otros cuidan de las 
cosas domésticas; otros son ayudantes (associatores). De las limosnas de los fieles hay necesidad para el sustento de los socios, aunque al presente, por los malos tiempos, soportan un gravamen de 2000 onzas de plata sellada. Por otra parte, del total del capital de 192.780 (onzas), recibese anualmente 9639 onzas de plata sellada que se gastan en la celebración de las misas y fiestas, dotación de doncellas y obras pías, de acuerdo con los deseos del benefactor. Acerca de estas dotaciones, el Provincial escribió a N. P. General el día primero de julio de 1747.

En el Catálogo Cuarto encontramos situado al P. Oviedo al hablar de la Casa Profesa, en los siguientes términos: Domus Professa Mexicana. P. Joannes Antonius de Oviedo, Praepositus..., etc.

Con el ejemplo que antecede queda elocuentemente manifiesta la importancia de los catálogos y la utilidad de nuestro ensayo, según así lo deseamos, para el investigador.

Hemos creído pertinente agregarle, como Apéndice, un catálogo de todos los jesuítas que durante el siglo xvi ejercieron sus ministerios en nuestra patria. Seguramente es incompleto, pues, a falta de catálogos de estos años, nos ha sido necesario empeñarnos en tun árido y laborioso trabajo de investigación cuyos frutos ofrecemos gustosamente al público estudioso. Los nombres han sido tomados de las obras de nuestros cronistas, tales como el Anónimo de la Relación Breve de 1602, publicado en este año por la Universidad Nacional de México, con notas, prólogo y adiciones del suscrito; Juan Sánchez Baquero, Relación de la Compañia de Jesís en México, Manuscrito de 1619, con notas del P. Ayuso, S. J.; Pérez de Rivas, Historia de los Triunfos y Corónica y Historia Religiosa, Madrid, 1645 y México, 1896, respectivamente; Florencia, Historia de la Compañia de Jesús en México, México, 1694; Oviedo, Menologio de Florencia, añadido, México, 1747 ; Alegre, Historia de la Compañia de Jesús, México, 1841-42; Dávila y Arrillaga, Continuación a Alegre, Puebla, 1888; Decorme, Historia de la Compañía de Jesús en México, durante el siglo XIX, Guadalajara, 1914. Estas dos últimas obras para la formación de algunos datos biográficos de los sujetos que alcanzaron los años posteriores a la primera expulsión. Nos hemos servido, por último, de algún material inédito que obra en el Archivo General de la Nación, en que se encuentran votos originales de los sujetos de la Compañía en diversas épocas. 
Para el arreglo de nuestro ensayo, en lo que a los impresos se refiere, hemos apurado las obras de León, Medina, Uriarte, Backer, Sommervogel, Iguíniz y Palau, en busca de noticias con que aumentar nuestro catálogo, aunque en ocasiones se consignan impresos desconocidos de estos bibliógrafos.

Hemos decidido también, para darle un poco más de interés a nuestro trabajo, agregar una pequeña biografía; inspirada en el mismo estilo de los catálogos, de las personas que intervinieron en su formación, y que son, en la mayoría de los casos, los Provinciales, según puede verse de su mismo contexto.

Francisco González de Cossío

\section{$\mathrm{NOTAS}$}

1 Ya en prensa este trabajo tuvo su autor noticia de ellos, por lo cual obran en forma de Adiciones al presente ensayo, más dos que encontró con posterioridad en el A. G. N. Véanse también las Adiciones al Apéndice.

2 El texto que sigue obra en lengua latina en el original, el cual se ha traducido para mayor comodidad del lector. 



\section{B I B L IOGR A F I A}

1674

XMMÉNEZ, Francisco.

1.-Cathalogus [sic] 3 Provinciae Mexicanae in fine Anni 1674.

MS. in fol.-El texto a continuación de lo anterior, ocupando 5 pp. s. n.

Carece de designación de autor; pero, según lo hemos visto, probablemente fué "confectus a Patre Francisco Ximénez", quien gobernó la Provincia desde julio de dicho año hasta el de 1677 , en que lo sustituyó el P. Tomás Altamirano.

No he podido encontrar noticia biográfica alguna acerca del P. Ximénez. El Catalogus Primus de esa fecha seguramente los contiene, pero no he podido dar con él, ni con el Secundus y Quartus, que indudablemente fueron formados en relación con éste que se describe.

1708

Jardón, Antonio.

2.-Catalogus Provinciae Mexicanae juxta ordinem Domorum, Collegiorum, et Residentiarum, et officiorum, quos in eis unusquisque habet sub initium Anni 1708.

MS. in fol.-El texto a continuación de lo anterior, ocupando $7 \mathrm{pp}$. s. n. a 2 cols.

No expresa el nombre de su autor. Nosotros suponemos como tal al P. Antonio Jardón, que en aquel tiempo era Provincial. "Natural de la ciudad de México, religioso de la Compañía de Jesús, cuyo instituto profesó en la provincia de la N. E. el año 1673. Fué maestro de latinidad, retórica y filosofía; y catedrático de teología moral, expositiva y escolástica. Gobernó los colegios de S. Ildefonso de México, el de la Puebla y el de Guatemala; y en 1709 [sic, por 1708], fué nombrado provincial de 
la N. E. Falleció siendo prefecto de estudios del colegio máximo de México en 1719." (Beristáin.)

Romano, Alejandro.

3.-Catalogus 4. Provintiae [sic] Mexicanae juxta ordinem Domorum, Collegiorum, Residentiarum, et officiorum, quae in eis unusquisque habet. die (en blanco) anno 1719.

MS. in fol.-El texto a continuación del título transcrito, ocupando 11 pp., la última apenas empezada.

Carece de designación de autor; pero en este tiempo era Provincial el P. Alejandro Romano, que duró en su encargo desde principios de dicho año hasta el de 1722.

Originario de Italia, probablemente de la capital, fué "... un hombre verdaderamente espiritual y religioso, pero de un genio duro, inflexible y nimiamente celoso de la regular observancia, en que no había para él faltas ligeras. Despidió de la Compañía a muchos, y hubieran sido muchos más, y de los sujetos que más ilustraron la provincia, si otros de las primeras personas de la Compañía no se le hubieran opuesto. Alegábase el que habiendo vivido muchos años en los fructuosísimos empleos de misionero y operario de indios, con grandes créditos de virtud y austeridad de vida, entró al gobierno de la provincia sin la experiencia que trae consigo el régimen de otros menores colegios. En su tiempo se proyectó y efectuó con rara prontitud la fundación del colegio que hoy tíene la Compañía en la ciudad de Celaya." (Alegre.) Sucediólo el P. José de Arjoó.

1720

Romano, Alejandro.

4.-Catalogus 3. rerum Provinciae Mexicanae Confectus die 20 julij, et Romae missus die 7 Augusti.

MS. in fol.-El texto a continuación del título, ocupando 10 pp. s. $n$. En el ángulo superior izquierdo de la primera: " 3 " Via de 7 de Agto. de 1720 ", y en la última la firma de Alejandro Romano.

1724

Arjoó, José de.

5.-Supplementum 1i. et 2 i. catalogi Provinciae Mexicanae a die $1^{3}$ Novembris Anni 1723 usque ad diem 30 Aprilis Anni 1724. 
MS. in fol.-El texto a continuación de lo anterior, ocupando $2 \mathrm{pp}$. s. n. a 2 cols., suscrito por el autor.

Fué el P. Arjoó natural de Zaragoza, en donde nació el año de 1663, habiendo ingresado a la Compañía en 1677. Hizo profesión de 4 votos desde 1696. Fué socio operario; Provincial desde 1722 hasta mediados de 1725, en que lo sucedió el P. Gaspar Rodero; Rector del Colegio Máximo y Prepósito de la Casa Profesa. Murió en Tepotzotlán en 1736.

1726

Rodero, Gaspar.

6.-Supplementum 1i. et 2i. Catalogi Provinciae Mexicanae a 15 die Martij anni 1725 usque ad 15 Aprilis 1726.

MS. in fol.-El texto a continuación del título, ocupando 2 pp. s. $n$. a 2 cols., y en la siguiente el sello de la Compañía, pero sin la firma del autor, a quien suponemos coma tal al P. Gaspar Rodero, cuyo provincialato duró sensiblemente el mismo lapso a que se refiere el suplemento que se describe, en la segunda ocasión en que asumió tal cargo.

He podido recoger muy pocos datos sobre el $P$. Rodero a propósito de su vida. El mismo Alegre nos habla apenas de él. (Vide t. IIr, págs. 165, 180 y 222 de su Historia.) Dejó escrita, y esto lo ignoró el doctor Beristáin, una relación de las Californias que en forma de memorial dirigió al Rey por los años de 1736, la cual fué impresa en España, y en tiempo de su procuración por la Compañía. (Vide Henry Wagner, The Spanish Soutb-West, etc., Berkeley, California.)

\section{7}

NIETo, Andrés.

7.-Supplementum 1i. et 2i. catalogi Prov. Mexicanae a 10 Junij usque ad diem 20 Decembris eiusdem anni 1727.

MS. in fol.-El texto a continuación del título, ocupando 2 pp. s. $n$. a 2 cols., y suscrito por el autor.

Fué el P. Nieto originario de La Roda, España, en donde nació el año de 1659. Ingresó en la Compañía en 1675. Hizo profesión de 4 votos en 1696. Fué Rector, Provincial de 1726 a 1729, y socio operario. Según el catálogo Segundo de 1730, era de ingenio suficiente, de buen juicio, de gran prudencia, de mucha experiencia, de suficiente aprovechamiento en letras, de temperamento colérico y con talento para gobernar y para los ministerios. 
Nieto, Andrés.

8.- Supplementum 1i. et 2 i. catalogi Prov. Mexicanae a die 20 Decemb. anni 1727 usque ad diem 7 Augusti anni 1728. a 2 cols.

MS. in fol.-El texto a continuación de lo anterior, ocupando $1 \mathrm{p}$.

Ya hemos visto que en este tiempo era Provincial el P. Andrés Nieto.

1729

Oviedo, Juan Antonio de.

9.-Supplementum primi, et secundi catalogi Provinciae Mexicanae a 7 die Augusti anni 1728 usque ad diem 9 Novembris anni 1729.

MS. in fol.-El texto a continuación del título anterior, ocupando 2 pp. s. n. a 2 cols.

Sobre los datos biográficos del P. Oviedo véase la introducción que precede a este ensayo. Solamente recordaremos aquí que el autor se hizo cargo por primera vez del provincialato el día 4 de noviembre de 1729 , correspondiéndole a él la confección de este suplemento.

\section{0}

Oviedo, Juan Antonio de.

10.-Catalogus 1us. Provinciae Mexicanae a P. Joanne Antonio de Oviedo Provinciali confectus et ad R. admodum P. N. Generalem missus die 15 Decembris Anno 1730.

MS. in fol.-Port., v. en bl., más 49 pp. de texto y 4 ff. de índice. Consigna 526 sujetos.

11.-Catalogus 2us. Provinciae Mexicanae a P. Joanne Antonio de Oviedo Provinciali confectus et ad R. admodum P. N. Generalem missus die 15 Decembris Anno 1730.

MS. in fol.-Port., v. en bl., más 49 pp.

12.-Catalogus 3us. Rerum Provinciae Mexicanae a P. Joanne Antonio de Oviedo Provinciali confectus die 1. Decembris Anno 1730, et ad R. admodum P. N. Generalem missus die 15 eiusdem mensis et anni.

MS. in fol.-Port., v. en bl., más $6 \mathrm{ff}$. 
13.- Supplementum 1i. et 2i. Catalogi Provinciae Mexicanae a die 22 Julij Anni 1730 usque ad diem 1s Decembris, eiusdem anni.

MS. in fol.-El texto a continuación del título, ocupando 2 pp. s. $n$. a 2 cols., suscrito por el autor.

1732

Barba, José.

14.-Supplementum 1i. et 2i. Catalogi Provinciae Mexicanae a die 23 Septembris anni 1732 usque ad diem 31 Decembris eiusdem anni.

MS. in fol.-El texto a continuación de lo anterior, ocupando 1 p. a 2 cols., suscrito por el autor.

El P. José Barba nació en Sevilla el año de 1671, habiendo entrado en la Compañía en 1689. Profeso de 4 votos desde 1705, enseñó Filosofía y Teología. Fué Rector, Provincial desde el 4 de noviembre de 1733 al 24 de febrero de 1736, y posteriormente Prepósito de la Casa Profesa. El catálogo segundo de 1730 consignaba su ingenio como óptimo, así como su juicio; la prudencia grande; mucha la experiencia; el aprovechamiento en letras óptimo; el temperamento melancólico, y con talento para todas las cosas.

\section{4}

Barba, José.

15.-Catalogus 3us. Rerum Provinciae Mexicanae a Pe. Josepho Barba Provinciali confectus die 1 Januarij anno 1734, et ad R. admodum P. N. Generalem missus anno 1734.

MS. in fol.-Port., v. en bl., más 11 pp. s. n. y suscrito por el autor.

16.- Supplementum 1i. et 2i. Catalogi Provinciae Mexicanae a die 31 Decembris, anni 1732, usque ad diem 24 Februarij anni 1734.

MS. in fol.--El texto a continuación de lo anterior, ocupando 2 pp. s. n. a 2 cols., y suscrito por el autor.

\section{5}

Barba, José.

17.-Supplementum 1i. et 2i. Catalogi Provinciae Mexicanae, a die 24 Februarij anno 1734, usque ad diem 20 Aprilis, anni 1735.

MS. in fol.-El texto a continuación del título anterior, ocupando 3 pp. s. n., a 2 cols., y suscrito por el autor. 
18.-Supplementum 1i. et 2i. Catalogi Provinciae Mexicanae a die 20 Aprilis, anno 1735, usque ad diem 31 Decembris, eiusdem anni 1735.

MS. in fol.-El texto a continuación de lo anterior, ocupando 1 p. a 2 cols., y suscrito por el autor.

1736

Peralta, Antonio de.

19.-Supplementum 1i. et 2i. Catalogi Provinciae Mexicanae a die 31 Decembris anno 1735 usq[ue] ad diem 4. Maij anno 1736.

MS. in fol.-El texto a continuación de lo anterior, ocupando $1 \mathrm{p}$. a 2 cols., suscrito por el autor.

Fué el P. Antonio de Peralta originario de esta ciudad de México, en donde nació el año de 1668. Abrazó el instituto de la Compañía en 1683, habiendo hecho profesión de 4 votos en 1702. Fué Prefecto de estudios y vicerrector. Enseñó Gramática, Filosofía y Teología. Encargóse del provincialato del 24 de febrero de 1736 al 3 de noviembre de dicho año. El catálogo segundo de 1730 dice fué su juicio e ingenio óptimos; su prudencia grande; su experiencia mucha; su aprovechamiento en las letras óptimo; su temperamento flemático y el talento para todas las cosas (ad omnia). El P. Gérard Decorme lo hace natural de Zumpango. (Vide La obra de los Jesuitas mexicanos durante la época colonial, etc.)

1737

Oviedo, Juan Antonio de.

20.-Supplementum 1i. et 2i. Catalogi Provinciae Mexicanae, a die 4 Maij anno 1736, usque ad diem 1. Martij anno 1737.

MS. in fol.-El texto a continuación de lo anterior, ocupando 2 pp. s. n, a 2 cols., y suscrito por el autor.

El segundo provincialato del P. Oviedo duró del 3 de noviembre de 1736 al 25 de junio de 1739, fecha en que lo sucedió el P. Mateo Ansaldo.

21.-Catalogus 1us. Provinciae Mexicanae a P. Joanne Antonio de Oviedo Provinciali confectus, et ad R. admodum P. N. Generalem missus die 1 Martij, Anno 1737.

MS. in fol.-Port., v. en bl., más 54 pp. de texto, más 5 ff. s, n. conteniendo el índice por orden alfabético de nombres de pila. Consigna 583 sujetos. 
22.-Supplementum 1i. et 2i. Catalogi Provinciae Mexicanae a die 1. Martij anno 1737, usque ad diem 24 Augusti eiusdem anni.

MS. in fol.-El texto a continuación de lo anterior, ocupando 2 pp. s. n. a 2 cols., suscrito por el autor.

1739

Ansaldo, Mateo.

23.- Supplementum 1i. et 2i. Catalogi Provinciae Mexicanae a die 22 Martij anni 1739, usque ad diem 24 Augusti eiusdem anni 1739.

MS. in fol.-El texto a continuación de lo anterior, ocupando $2 \mathrm{pp}$. s. n. a 2 cols., suscrito por el autor.

El P. Mateo Ansaldo nació en Génova el año de 1689. Ingresó en la Compañía en 1708. Profeso de 4 votos desde 1725, enseñó Gramática, Filosofía y Teología. Fué maestro de novicios, Rector del Colegio Máximo y Provincial desde el 25 de junio de 1739 hasta principios de 1743, fecha en que lo sucedió el P. Cristóbal de Escobar y Llamas. Según el catálogo segundo de 1744, era de ingenio bueno; de juicio óptimo; de gran prudencia; de mucha experiencia; de buen aprovechamiento en letras; de temperamento templado, y con talento para todas las cosas.

Oviedo, Juan Antonio de.

24.-Supplementum 1i. et 2i. Catalogi Provinciae Mexicanae a die 8 Julij anno 1738 usque ad diem 22 Martij anno 1739.

MS. in fol.-El texto a continuación del título, ocupando 2 pp. s. n. a 2 cols., suscrito por el autor.

1740

Ansaldo, Mateo.

25.- Supplementum 1i. et 2i. Catalogi Provinciae Mexicanae a die 24 Augusti ann. 1739 usque ad diem $4 \mathrm{Maij}$ ann. 1740.

MS. in fol.-El texto a continuación del título anterior, ocupando 2 pp. s. n. a 2 cols., suscrito por el autor.

$$
1741
$$

Ansaldo, Mateo.

26.-Supplementum 1i. et 2i. Catalogi Provinciae Mexicanae a die 4 Maij anni 1740, usque ad diem 31 Januarij anni 1741.

MS. in fol.-El texto a continuación de lo anterior, ocupando $2 \mathrm{pp}$. s. n. a 2 cols., suscrito por el autor. 
Escobar y Llamas, Cristóbal de.

27.-Supplementum 1i. et 2i. Catalogi Provinciae Mexicanae a die 31 Januarij anni 1741, usque ad diem 29 Martij anno 1743.

MS. in fol.-El texto a continuación de lo anterior, ocupando $4 \mathrm{pp}$. s. n. a 2 cols., suscrito por el autor.

El P. Escobar y Llamas nació en Tingüindín el año de 1693. Entró en la Compañía en 1714. Enseñó Gramática, Filosofía y Teología. Fué por algún tiempo superior del seminario de San Ildefonso. Bachiller en Filosofía, profesó en los 4 votos desde 1728. Provincial desde principios de 1743 a principios de 1747, año en que lo sucedió el P. Juan María Casati. El P. Decorme lo hace natural de Valladolid, hoy Morelia. Según el catálogo segundo de 1744, fué nuestro autor de óptimo ingenio; de buen juicio; de prudencia grande; de mucha experiencia; de óptimo aprovechamiento en letras; de temperamento colérico y de talento para cualquier cosa.

\section{4}

Escobar y Llamas, Cristóbal de.

28.-Catalogus 1us. Provinciae Mexicanae a P. Christophoro de Escobar Provinciali confectus et ad Rm. admodum P. N. Generalem missus die 18 Maij anno 1744 . numerar.

MS. in fol.-Port., v. en bl., más 52 pp. de texto, la última sin

29.-Catalogus 2us. Provinciae Mexicanae a P. Christophoro de Escobar Provinciali confectus, et ad R. admodum P. N. Generalem missus die 18 Maij anno 1744.

MS. in fol.-Port., v. en bl., más 60 pp. s. n., siendo las 8 primeras el índice alfabérico por nombres de pila.

30.-Catalogus 3us. rerum Provinciae Mexicanae a P. Christophoro de Escobar Provinciali confectus, et ad Romam missus die 18 maij Anno 1744.

MS. in fol.-Port., v. en blanco, más 14 pp. s. n.

31.-Catalogus 4us. Provinciae Mexicanae a P. Christophoro de Escobar Provinciali confectus, et ad R. admodum P. N. Generalem missus die 18 maij anno 1744 .

MS. in fol.-Port., v. en bl., más 8 pp. s. n. a 2 cols. 
32.-Supplementum 1i. et 2i. Catalogi Provinciae Mexicanae a die 29 Martij usque ad diem 18. Maij anni 1744.

MS. in fol.-El texto a continuación de lo anterior, ocupando $2 \mathrm{pp}$. s. n. a 2 cols.

Escobar y Llamas, Cristóbal de.

33.-Supplementum 1i. et 2i. Catalogi Provinciae Mexicanae a die 18 Maij anni 1744 usque ad diem 30 novembris anni 1745 .

MS. in fol.-El texto a continuación de lo arterior, ocupando $3 \mathrm{pp}$. s. n. a 2 cols., suscrito por el autor.

\section{7}

Casati, Juan María.

34.- Supplementurn 1i. et 2i. Catalogi Provinciae Mexicanae a die 30 Novembris anni 1745 usque ad diem 12 Februarii anni 1747.

MS. in fol.-El texto a continuación de lo anterior, ocupando $2 \mathrm{pp}$. s. n. a 2 cols., suscrito por el autor.

El P. Juan Maria Casati, originario de Milán, nació el 8 de marzo de 1691. Hizo su entrada en la Compañía el 9 de diciembre de 1709. Profeso de 4 votos desde el 15 de agosto de 1725, fué Provincial desde principios de 1747 hasta marzo de dicho año, en que lo sustituyó el $P$. Andrés Xavier García, y murió el 26 de septiembre de 1764 en el Colegio de San Andrés de esta ciudad.

1748

García, Andrés Xavier.

35.-Catalogus 1us. Provinciae Mexicanae a P. Andrea Xaverio Garcia Provinciali confectus, et ad Rum. admodum P. N. Generalem missus die $1^{\text {a }}$ julij anno 1748 .

MS. in fol.-Port., v. en bl., más 52 pp. de texto, más 4 ff. s. n. de índice a 2 cols.

Consigna 579 sujetos.

Originario de Extremadura, el P. García nació el 3 de diciembre de 1686, habiendo ingresado en la Compañía el 27 de enero de 1705. Hizo profesión de 4 votos el 15 de agosto de 1720. Fué operario de indios, socio provincial, procurador en Roma, visitador general de misiones, Rector, Prepósito de la Casa Profesa y Provincial desde marzo de 1747 
hasta el 31 de agosto de 1750. No sé cuándo murió, pero en 1764 se encontraba en el Colegio de San Gregorio de México, y el catálogo de Zelis no lo consigna ya. Debió haber sido entre 1764 y 1767, pues no aparece como expulso. El catálogo de 1751 dice era de ingenio bueno; de óptimo juicio; de mucha prudencia; de experiencia mucha también; de buen aprovechamiento en letras; de temperamento templado, y de talento para todas las cosas.

36.-Catalogus 2us. Provinciae Mexicanae a P. Andrea Xaverio Garcia Provinciali confectus, et ad Rum. admodum P. N. Generalem missus die $1^{a}$ Julij anno 1748 .

MS. in fol.-Port., v. en bl., más 52 pp. y en la siguiente la firma del autor.

37.-Catalogus 3 us. Rerum Provinciae Mexicanae, a Pe. Andrea Xaverio Garcia Provinciali confectus, \& ad Romam missus die $1^{3}$ Julij anno 1748.

MS. in fol.-Port., v. en bl., más 12 pp. s. n.

38.-Catalogus 4us. Provinciae Mexicanae a P. Andrea Xaverio Garcia Provinciali confectus et ad R. admodum P. N. Generalem missus die 1 julij anno 1748.

MS. in fol.-Port., v. en bl., más 6 pp. s. n. a 2 cols.

39.-Supplementum 1i. et 2i. Catalogi Provinciae Mexicanae a die 12 februarij anni 1747 usque ad diem 20 Aprilis anni 1748.

MS. in fol.-El texto a continuación de lo anterior, ocupando 2 pp. s. n. a 2 cols.

40.-Supplementum 1i. et 2i. Cathalogi [sic] Provinciae Mexicanae a die 20 Aprilis anni 1748 ad diem 1 Julij ejusdem anni.

MS. in fol.-El texto a continuación de lo anterior, ocupando 1 p. a 2 cols.

41.-Supplementum 1i. et 2i. Catalogi Provinciae Mexicanae a die $1^{2}$ Julij anni 1748 ad diem 31 octobris ejus anni.

MS. in fol.-El texto a continuación de lo anterior, ocupando 2 pp. s. n. a 2 cols., suscrito por el autor. 
García, Andrés Xavier.

42.-Supplementum 1i. et 2i. Catologi [sic] Provinciae Mexicanae a die 31 octobris anni 1748 usque ad diem 15 Junij anni 1749.

MS. in fol.-El texto a continuación de lo anterior, ocupando 2 pp. s. n. a 2 cols.

1750

García, Andrés Xavier.

43.-Supplementum 1i. et 2i. Cathalogi [sic] Provinciae Mexicanae a die 15 Junij anni 1749 usque ad diem $1 \mathrm{am}$. Aprilis anni 1750.

MS. in fol.-El texto a continuación del título, ocupando 2 pp. s. n. a 2 cols., y suscrito por el autor.

ReTz, Francisco.

44.-Catalogus Sociorum, qui missi sunt ad Provinciam Mexicanam, anno 1750 (cum) Superiore P. Ignatio Coromina.

MS. in fol.-El texto a continuación de lo anterior, ocupando 4 pp. s. n.

Consigna 48 sujetos enviados.

El P. Francisco Retz fué originario de Bohemia, y General de la Compañía del 30 de noviembre de 1730 al 19 del mismo mes de 1750 .

El P. Ignacio Coromina nació en Olot, villa del obispado de Gerona, en Cataluña, a 24 de octubre de 1709. Recibió en la Universidad de Cervera el grado de Bachiller en Artes, Teologia y Cánones, y luego se consagró a Dios en la Compañía de Jesús en el noviciado de Tarragona a 30 de septiembre de 1733. Enseñó la latinidad en el Colegio del Monte Sión de la isla de Mallorca, y fué ministro operario en la Casa Profesa de Valencia y en el Colegio de Barcelona, y Rector del de Vique. Habiendo muerto el P. Paz, procurador de los jesuítas de la Nueva España, lo nombró el Prepósito General Retz para que condujese a México la misión del año 1749, y trajo en efecto a esta América 48 jesuítas. Aquí fué socio y secretario del Provincial, y Rector del Colegio de Guanajuato, donde falleció con sentimiento general y fama de santidad a 21 de junio de 1763. Era matemático excelente, y explicó estos conocimientos en el ramo de arquitectura, no sólo en Vique, donde monteó y dirigió desde los cimientos hasta su conclusión la obra del noviciado, sino también en Guanajuato, dilatando el plano en que se fabricó el magnífico colegio de la Compañía, y viviendas que para misioneros fundó don Pedro Retana en un sitio estrecho, cuya extensión impedían los peñascos del cerro. (Beristáin.) 
Baltasar, Juan Antonio.

45.-Catalogus 1us. Provinciae Mexicanae a P. Joanne Antonio Balthasar Provinciali confectus, et ad R. admodum P. N. Generalem missus die 1 Decembris, anno 1751.

MS. in fol.-Port., v. en bl., más 56 pp. de texto y 7 pp. s. n. a 2 cols., de índice.

Consigna 624 sujetos, y parece ser el que salió impreso en dicho año. Véase la correspondiente descripción.

El P. Baltasar, originario de Lucerna, Suiza, nació el 10 de abril de 1697, habiendo ingresado en la Compañia el 26 de octubre de 1712 y hecho profesión de 4 votos el 15 de agosto de 1730 . Gobernó la provincia desde el 15 de agosto de 1750 hasta el 14 del mismo mes, de 1753. Murió el 23 de abril de 1763 .

46.-Catalogus 2us. Provinciae Mexicanae a P. Joanne Antonio Balthasar Provinciali confectus, et ad R. admodum P. N. Generalem missus die 1. Decembris, anno 1751 .

MS. in fol.-Port., v. en bl., más 56 pp., y en la siguiente la firma del autor.

47.-Catalogus 3us. Rerum Provinciae Mexicanae a P. Joanne Antonio Balthasar Provinciali confectus, et ad Romam missus die 1. Decembris, anno 1751 .

MS. in fol.-Port., v. en bl., más 10 pp. s. n.

48.-Catalogus 4us. Provinciae Mexicanae a P. Joanne Antonio Balthasar Provinciali confectus, et ad R. admodum P. N. Generalem missus die 1. Decembris, anno 1751.

MS. in fol.-Port., v. en bl., más 8 pp. s. n. a 2 cols,

49.-Catalogus / Perfonarum, \& Domiciliorum, in quibus fub / A. R. P. (en blanco) Societatis Jesv / Praeposito generali XVI. / P. Petro Zespedes Hispaniarvm Assistente. / P. Joanne Antonio Balthazar Provin- / ciae Mexicanae Praeposito provinciali LXVI. / Societas Jesv Mexicana pro Gloria Dei ex / inftituto laborat. / Patribvs conscriptis / in / habitis Almae totius Provinciae Comitijs / dicatus, \& consecratus. / (linea de adorno) Mexici: / Ex Regalis, \& Antiquioris Divi Ildephonsi Collegij Typographia. Anno M.DCC.LI. 
in 4to. apaisado.-Port., v. en bl., 4 ff. prels. s. n. (la $3^{a}$ más larga que las restantes). 7 ff. $\mathrm{s}$. $\mathrm{n}$. con el $\mathrm{v}$. de la última en bl., y 1 f. para el Catalogus ordine domorum, collegiorum, residentiarum, missionum et officiorum quae singuli in illis habent. $-6 \mathrm{ff}$. s. n. (la primera orlada $y$ con el $v$. en $b l$.) para el Catalogus nomina et cognomina sociorum, patriam, aetatem, annum insuper quo fuum quifque nomen Societatis nostrae dedit, exhibens. Una f. bl., más $S$ ff. s. n. con el v. de la $2^{a}$ en bl., más una $f$. bl., más otra para el Lectori benevolo, más $4 \mathrm{ff}$. s. n. para Convictores Regalis et Antiquioris Seminarii Mexicani Divi Ildephonfi, con el v. de la última en bl.

En los preliminares se encuentran: Dedicatoria, o prólogo dirigido al Seminario de S. Ildefonso; Index Provinciarum; Status universae Societatis Jesu anno 1750; Syllabus Patrum Generalium; Syllabus Patrum Provincialium qui Provincia huic Mexicanae ab ejus exordio praefecti sunt.

León lo atribuye indebidamente al P. Lucas Rincón, y el P. Uriarte lo supone salido de la pluma del P. Manuel Colazo, fiado en lo que asienta Hervás en su Catálogo de las Lenguas. Medina acierta al reconocer al P. Baltasar como su autor, según se desprende del antecedente MS. ya consignado.

León, Bib. Mex., parte v, n. 461, p. 424.

Uriarte, Catálogo Razonado, t. I, n. 341, p. 119.

Medina, La Imp. en Méx., t. v, n. 4035, p. 154.

Iguíniz, Bib. Biog., n. 179, p. 68.

1755

Calderón, Ignacio.

50.-Catalogus 1us. Provinciae Mexicanae a P. Ignatio Calderon Provinciali confectus, et ad $R$. admodum P. N. Generalem missus die 19 Januarii, anno 1755 .

MS. in fol.-Port., v. en bl., más 15 pp. s. n. de la lista por orden alfabético de nombres de pila de los sujetos, en relación a su origen, fecha de nacimiento y lugar en que actualmente se encuentran, más 44 pp. de texto, más 7 pp. s. n. de índice.

Consigna 624 sujetos.

El P. Calderón fué originario de Durango, en donde nació el 6 de mayo de 1696. Entró a la Compañía el 13 de octubre de 1714, e hizo profesión de 4 votos el 13 de abril de 1732. Enseñó Gramática y Filosofía. Fué Superior del Seminario de San Ildefonso; Rector; Provincial, y Operario. Bachiller en Filosofía, era de grande ingenio y de óptima prudencia y juicio; de mucha experiencia y de grande aprovechamiento en letras; 
de temperamento colérico y con talento para muchas cosas. Murió en el mar, camino del destierro, el 5 de noviembre de 1767.

51.-Catalogus 2us. Provinciae Mexicanae a P. Ignatio Calderon Provinciali confectus, et ad R. admodum P. N. Generalem missus die 19 Januarii 1755.

MS. in fol.-Port., v. en bl., más 44 pp. En la siguiente, s. n., el sello y firma del autor.

52.-Catalogus 3 us. Rerum Provinciae Mexicanae a P. Ignatio Calderon Provinciali confectus, et Romam missus die 19 Januarii 1755.

MS. in fol.-Port., v. en bl., más 10 pp. s. n.

1756

ANónIMo.

53.-IHS Catalogo de los Nombres, Patrias, Edades, Entradas y Grados de los Sujetos de la Compañía de Jesus de esta Provincia de Nueva-España. Agosto 15 de 1756. blanco.

MS. in 4to. apaisado.-Port. orlada, v. en bl., más 26 ff., algunas en

Formado seguramente por algún curioso, que compuso la lista por orden de fechas de las profesiones de 4 votos de los jesuítas consignados.

Carta, Agustín.

54.-† / Catalogus / eorum patrum, qui Procuratores nominari possunt, in / Comitijs Provinciae Mexicanae Societatis Jesu, habendis die 2. Mensis Novembris / labentis anni 1757. / Praeside Patre Augustino Carta Provinciali.

in fol. doble, orlado, impreso en una cara.

Consigna 251 sujetos.

El P. Agustín Carta nació en Cerdeña el 31 de mayo de 1698. Entró en la Compañía el mismo día y mes de 1716; hizo profesión de 4 votos el 5 de agosto de 1733 y murió el 8 de agosto de 1767 , esperando su turno para el destierro. Fué Provincial hasta principios de 1760 , en que lo sustituyó el P. Pedro Reales.

González de Cossío, La Imp. en Méx., 100 adiciones a Medina, núm. 45 , en que se reproduce en facsímil. 
1758

Carta, Agustín.

55.-Catalogus 2us. Provinciae Mexicanae a P. Agustino Carta Provinciali confectus et ad R. admodum P. N. Generalem missus die 12. Junij 1758.

MS. in fol.-Port., v. en bl., más 61 pp.

Consigna 684 sujetos, $y$ es probablemente el origen del catálogo impreso que se describe a continuación.

56.-(†) - / Catalogus / Provinciae Mexicanae / Societatis Jesu, / In quo Singulorum Nomen, Cognomen, Patria, / AEtas, atque Ingreffus in eamdem continetur. / (Colofón:) Mexici: ex Regalis \& Antiquioris Divi Ildefonfi Collegij Typis, Anno Domini 1758.

in 4to.-El texto a continuación de lo anterior, ocupando $26 \mathrm{pp}$. s. n., 4 de ellas blancas, incluso la última, y a 4 cols., separadas por filetes.

Hervás, en su Catálogo de las Lenguas, t. I, p. 286, nota, lo atribuye al P. Manuel Colazo. Medina lo consigna como anónimo. Lo hemos atribuído nosotros al P. Carta por haber sido formado durante su provincialato.

1759

Carta, Agustín.

57. - † / Supplementum primi, / et secundi catalogi / Provinciae Mexicanae á die 12 Junij 1758, usque ad diem 26/Augusti 1759.

in 4 to.-El texto a 2 cols., e inmediatamente abajo del título, ocupando 2 pp. s. n., más 1 f. bl.

Consigna los difuntos en el término señalado; los que emitieron votos post biennium en 1758; los que lo emitieron en 1759; los que hicieron profesión de 4 votos en 1757 [sic]; los formados Coadjutores espirituales y temporales en dicho término; los admitidos en la Sociedad en el mismo; los separados de ella en 1758 y 1759 , y los iniciados en las Sagradas Ordenes los días 23 y 29 de septiembre y 1 de octubre de 1758, y los días 23 y 31 de diciembre de dicho año y 6 de enero de 1759.

González de Cossio, La Imp. en Méx., 100 adiciones a Medina, núm. 49 , en donde se reproduce. 
Rrcci, Florentino.

58.- Catalogus eorum qui ad Provincias Indiaurum [sic] missi sunt ab Anno 1758. ad Annum 1761.

in 4 to. $-1 \mathrm{f}$.

Uriarte, Catálogo, núm. 6249 , t. Iv, p. $\$ 11$.

Reales, Pedro.

59.-Catalogus 1us. Provinciae Mexicanae a P. Petro Reales Provinciali confectus, et ad R. admodum P. N. Generalem missus die 12 Julii 1761.

MS. in fol.-Port., v. en bl., más 64 pp. de texto, más 8 pp. s. n. a 2 cols. de. índice.

Consigna 704 sujetos.

Su autor fué originario de Fuente del Sol, en donde nació el 23 de abril de 1704, habiendo abrazado el instituto de la Compañía el 18 de abril de 1722. Fué Provincial desde principios de 1760 hasta el 19 de mayo de 1763, sorprendiéndolo la expulsión cuando era Rector del Colegio Máximo de San Pedro y San Pablo de México. Murió en Veracruz, antes de la llegada de su turno para el exilio, el 23 de agosto de 1767.

60.-Catalogus 2us. Provinciae Mexicanae a P. Petro Reales Provinciali confectus, et ad R. admodum P. N. Generalem missus die 12 Julii 1761 .

MS. in fol.-Port., v. en bl, más 64 pp. En la siguiente, s. n., la firma del autor.

61.-Catalogus Rerum Provinciae Mexicanae Romam missus die 12 Julij 1761 .

MS. in fol.-El texto a continuación de lo anterior, ocupando $16 \mathrm{pp}$. s. n. y suscrito por el autor.

Trátase del catálogo tercero de la colección de este año.

$$
1764
$$

Ricci, Lorenzo.

62.-Catalogus eorum, qui ad Provincias Indiarum missi sunt. Ab Anno 1761. ad Ann. 1764.

in 4to.-Una foja.

Uriarte, Catálogo Razonado, t. IV, n. 6249, p. 511. 
Zevalios, Francisco.

63.-Catalogus 1us. Provinciae Mexicanae a Patre Francisco Zevallos Provinciali confectus, et ad Reverendm. Patrem Nostrum Generalem missus die 28 Decembris, anno 1764.

MS. in fol.-Port., v. en bl., más 61 pp. de texto y 8 pp. s. n. de índice a 2 cols., suscrito por el autor.

Consigna 675 sujetos.

Fué el P. Zevallos natural de Antequera de Oaxaca, en donde nació el 13 de octubre de 1704. Ingresó en la Compañía el $1^{\circ}$ de junio de 1720, habiendo hecho profesión de 4 votos el 15 de agosto de 1739 . Fué Provincial de 1763 a 1766; sufrió la expulsión y murió en Bolonia, el 27 de febrero de 1770 .

64.-Catalogus / Personarum, et Offi- / ciorum Provinciae Mexicanae / Societatis Jesu. / In Indijs 1764./ (el escudo de la Compañia) (linea de adorno) Mexici. / Typis Reg. \& Ant. D. Ildefonsi/Seminarij Collegij.

in 8vo.-Port. orlada, v. en bl.-Una f. con el Index Alphabeticus collegiorum, et domorum; et insuper Provinciarum Missionum Mexicanae Provinciae.-Texto: $1-55$ pp. y final bl.

Tanto el doctor León como Medina y el P. Uriarte, lo consignan como anónimo; sin embargo, es evidente haber sido su autor el $\mathrm{P}$. Zevallos, concordando el número de sujetos en este catálogo y en el anterior manuscrito. a la 118.

León, Bib. Mex., Pte. IIr, n. 44, en donde se reproduce desde la p. 76

Medina, La Imp. en Méx., t. v, n. 4867, p. 490.

Uriarte, Cat. Razonado, t. IV, n. 6256, p. 513 .

Iguíniz, Bib. Biog., n. 181, p. 68 :

65.-( $)$ † ( - / Supplementum primi, / et secundi catalogi Provinciae Mexica- / nae a die 26. Martij 1764. usque ad diem 28. / Decembris ejusdem anni 1764 .

in 4to.-El texto a continuación del título transcrito, contenido en 2 pp. s. n.

Consigna los difuntos en 1763 y 1764; los admitidos en su término en la Sociedad; los que emitieron votos después del bienio; los iniciados en las Sagradas Ordenes; los que hicieron profesión de 4 votos, y los separados de la Sociedad. 
González de Cossío, La Imp. en Méx., 100 adiciones a Medina, núm. 57 , en donde se reproduce íntegro.

1769

ANóNIMO.

66.-Catalogus Personarum Provinciae. Quae olim fuit Novae Hispaniae, Societatis Jesu, stabilitae in Legationibus Bononiensi, et Ferrariensi, Italicis. Anno Domini MDCCLXIX.

in 8 vo.-23 pp. (Sin pie de imprenta.)

Uriarte, Cat. Raz., t. Iv, n. 6256, p. 513 .

1820

Cantón, Pedro.

67.-Catalogus / Sociorum Provinciae Mexicanae/Societatis Jesu / et munerum quibus quisque fungitur / Mens. Febr. ann. MDCCCXX. / Ad maiorem Dei gloriam. / (Viñeta con un IHS) Mexici / ex officina Alexandri Valdes.

in 4 to.-Port., v. en bl., más 11 pp. y final bl.

Fué el P. Cantón originario de Guadalajara, México, en donde nació el 14 de febrero de 1745, habiendo entrado en el noviciado el 15 de julio de 1761, en el Colegio de San Juan, antiguo seminario de los jesuítas en aquella ciudad. Fué sucesor inmediato del Provincial P. Castañiza, quien murió el 24 de noviembre de 1816, y gobernó la Provincia hasta la expulsión de 1821 .

Medina, La Imp. en Méx., t. viI, p. 194, n. 11567.

Dávila y Arrillaga, Hist. de la Comp. de Jesús (continuación), t. II, p. 224.

1871

Zelis, Rafael de, y Márquez, Pedro José.

68.-Catalogo / de los sugetos / de la Compañía de Jesus / que formaban / la Provincia de México/el dia del arresto, / 25 de junio de 1767. / (filete) Contiene: / los sugetos por orden alfabético, por orden de edad, por orden de grado: / los colegios, las misiones y los difuntos. / (pequeño bigote) Comenzado en Roma por don Rafael de Zelis / el dia 27 de junio, / y terminado el 23 de agosto de 1786. / (viñeta) México / imprenta de I. Escalante y Ca. / Bajos de San Agustin, numero 1. / ( pequeño filete) 1871. 

indice.

in 4to.-Port., v. en bl.-Texto: 3-202, más otras 2 pp., s. n., de

Al final de la primera pág. se asienta que “... Después de la muerte del P. Zelis († 1798), continuó la lista de difuntos el P. Pedro Márquez; y más tarde, vino á parar el manuscrito en manos del Sr. D. A. M. ..."

El P. Zelis nació en Veracruz el 23 de octubre de 1747, habiendo entrado en la Compañía el 6 de marzo de 1765. Murió en Bolonia, de 51 años de edad, el 25 de junio de 1798.

El P. Márquez fué originario de San Francisco del Rincón, Gto., en donde nació el 22 de febrero de 1741. Hizo su entrada en la Compañía el 4 de marzo de 1761. Para el conocimiento de la ajetreada vida de este jesuíta, véase su biografía escrita en latín por el $P$. Corral.

\section{ADICIONES A LA BIBLIOGRAFIA}

\section{6}

Palacios, Juan de.

1.-Catalogus 2us. Provinciae Mexicanae Societatis Jesu Transmissus Romam ad R. P. N. Generalem die 30 Maij Anno 1696.

MS. in fol.-Port., v. en bl., 43 pp. s. n. de texto, más una última pág. en bl.

Suscrito por su autor, el P. Juan de Palacios, que gobernó la Provincia desde el día 8 de enero de 1696, fecha en que se abrió el pliego de gobierno y en que venía señalado como sucesor del P. Diego de Almonacir, hasta el 6 de enero de 1699, en que le sucedió el P. Francisco Arteaga. Fué el P. Palacios quien concedió al benemérito P. Juan María de Salvatierra licencia para entrar a las Californias.

Archivo General de la Nación.

1725

ANónimo.

2.-Catalogo en que se asientan los Nombres, Patria, Edad, Entrada y Grado de los sujetos de la Compañía de Jesvs en esta Provincia de Nueva España. Año de 1725. 
MS. in 4to. apaisado.-Port., v. en bl.; 13 ff. s. n.; más 3 ff. bl.; más 5 pp. s. n. con los Hermanos Coadjutores Formados; más 4 pp. s. n. con los Hermanos Coadjutores no Formados; más 1 p. s. n. bl.

A pesar de la fecha de la portada, se registra hasta el Hermano Bernardo Lazcano, que fué recibido en 1729.

Biblioteca Nacional de México, sección de manuscritos.

1729

ANónimo.

3.-Catalogo en que se asientan los Nombres, Patria, Edad, Entrada, y grado de los sujetos de la Compa. de Jesvs en esta Provincia de Nueva España. Año de 1729.

MS. in 4to. apaisado.-Port., v. en bl.; 5 ff. s. n. para los Profesos de 4 Votos; más 2 ff. s. n. para los Padres Coadjutores Espirituales; más 7 ff. s. n. con los Padres y Hermanos Escholares; más 7 ff. s. n. con los Hermanos Coadjutores Formados; más 1 f. bl.; más 1 p. s. n. con los. Padres y Hermanos Escolares; más 5 pp. bl.

A pesar de la fecha de la portada, consigna hasta el Hermano Basilio del Solar, recibido en 1745 .

Biblioteca Nacional.

1733

ANónIMO.

4.-Cathalogo [sic] en que se asientan los nombres, Patria, edad, entrada y Grado de los sugetos de esta Prova. de Na. España. Año de 1733.

MS. in 4to. apaisado.-Port., v. en bl.; 7 ff. sı n.; más $3 \mathrm{ff}$. blancas; más 1 p. s. n. con los Padres Profesos de 3 Votos; más 1 f. bl.; más 2 ff. s. n. con los Padres Coadjutores Espirituales; más 1 f. bl.; más 7 ff. s. $n$. con los Padres y Hermanos Escolares; más 5 ff. bl.; más 2 ff. s. n. con los Hermanos Coadjutores Formados; más 2 ff. bl.; más 3 pp. s. n. con otros Hermanos Coadjutores Formados (serán éstos los no formados?); más 11 pp. bl.

Biblioteca Nacional.

1741

Ansaldo, Mateo.

5.-Catalogus 2us. Provinciae Mexicanae a P. Mattheo Ansaldo Provinciali confectus, et ad R. admodum P. N. Generalem missus die 31 Januarij anno 1741 .

MS. in fol.-Port., v. en bl.; 53 pp. de texto, más 3 pp. s. n. en bl. Archivo General de la Nación. 
Anónimo.

6.-Nombres de los Padres Generales. (Lo anterior casi totalmente borrado con acuarela.)

MS. in 4to. apaisado.-Un gran escudo de la Compañía a colores de acuarela, sirviendo de anteportada. El texto a continuación del título anterior, ocupando: 1 p. s. n. para los PP. Generales; v. en bl.; 2 pp. s. n. con los PP. Provinciales y Visitadores que han sido de esta Provincia; $1 \mathrm{f}$. bl.; 9 ff. s. n. para los Padres Profesos de 4 votos, cuyo título está cercado por una orla iluminada; 3 ff. bl.; más 1 f. s. n. para los Padres Profesos de 3 votos; más 2 ff. bl.; más 9 ff. s. n. con los Padres y Hermanos Escolares; más 1 f. bl.; más 4 ff. s. n. con los Hermanos Coadjutores Formados; más 4 ff. bl.; más 2 ff. s. n. para los Hermanos Coadjutores no formados; más $4 \mathrm{ff}$. bl.; más $1 \mathrm{f}$. s. $n$. con un resumen de los sujetos catalogados, que hacen un total de 565 ; más $1 \mathrm{f}$. bl. final.

Biblioteca Nacional.

1750

Anónimo.

7.-Catalogo de los Nombres, Patrias, Edades, Entradas y Professiones de los Sujetos de la Compañia de Jesus de esta Provincia de nueva España. Año de 1750.

MS. in 4to. apaisado.-Port., v. en bl; 6 ff. s. n. con los Profesos de 4 votos; más 2 ff. bl.; más 1 p. s. n. con los Profesos de 3 votos; más 1 p. bl.; más 1 f. s. n. con los Padres Coadjutores Espirituales; más 1 f. bl.; más 13 pp. s. n. con los Padres y Hermanos Coadjutores Formados; más 1 f. bl.; más 3 pp. con los Hermanos Coadjutores no Formados; más 3 pp. bl. finales.

No obstante la fecha de la portada, consigna hasta el Hermano Juan' Morlete, recibido en 1753.

Biblioteca Nacional.

ANónImo.

8.-Padres Professos de 4 Votos. 1750.

MS. in 4to. apaisado.- El texto a continuación del título, ocupando 5 ff. Siguen los Padres y Hermanos Escolares, que están consignados en las hojas 12 y 17, faltando de la 6 a la 11 y de la 13 a la 16, inclusive; sigue la foja 18 en bl. y en las 19 y 20 los Hermanos Coadjutores Forma- 
dos; en seguida la foja 21 en bl. y en las 22 y 23 los Hermanos Coadjutores no Formados. Las ff. 24 y 25 en bl.

Biblioteca Nacional.

1756

ANónimo.

9.-Padres Professos de 4 Votos. 1756.

MS. in fol. apaisado.-El texto a continuación del título anterior, ocupando 6 ff. s. n. para los Profesos de 4 votos; más 1 f. bl.; más 1 p. s. n. con los Profesos de 3 votos; más 1 p. bl.; más 1 f. s. n. con los PP. Coadjutores Espirituales; más 2 ff. bl.; más 13 pp. s. n. con los PP. y HH. Escolares; más 1 p. bl.; más 2 ff. s. n. con los HH. Coadjutores Formados; más 1 f. bl.; más 3 pp. s. n. con los HH. Coadjutores no Formados; más 7 pp. bl.; más una relación de difuntos en la cara interna de la pasta.

Biblioteca Nacional.

$$
1760
$$

ANónimo.

10.- IHS Catalogo de los Nombres, Patrias, Edades, Entradas, y Grados de los Sujetos de la Compañía de Jesus de esta Provincia de Nueva España. Febrero 26 de 1760.

MS. in 4to. apaisado._Port. orlada a colores, v. en bl.; más $8 \mathrm{ff}$. s. n. con los Padres Profesos de Quatro Votos; más $2 \mathrm{ff}$. bl.; más 1 f. s. n. con los Padres Professos de Tres Votos; más 1 f. s. n. con los Padres Coadjutores Espirituales; más 2 ff. bl.; más 17 pp. s. n. con los Padres, y Hermanos Escolares; más 3 pp. bl.; más 3 ff. s. n. con los Hermanos: Coadjutores Formados; más 1 f. bl.; más 2 ff. con los Hermanos Coadjutores no Formados; más $3 \mathrm{ff}$. bl.

Biblioteca Nacional. 


\section{A P E N D I C E \\ CATALOGO DE LOS SUJETOS DE LA COMPAÑIA DE JESUS QUE, EN EJERCICIO DE SUS MINISTERIOS, ESTUVIERON EN NUEVA ESPAÑA DURANTE EL SIGLO XVI}

(Se ha procurado dar la noticia de su nacimiento; de su entrada en la Compañía; de su estancia en Méxi$c o, y$ de su muerte, salida o expulsión, en la medida del éxito en nuestras investigaciones.)

1 Acosta, Bernardino.-P.-Nació en Medina del Campo, 1538; entró en la Cía. en 1553; pasó a México en la expedición de 1579; murió en México, 1615.

2 Alarcón, Pedro.-H.-Nació ... ; entró en la Cía...; pasó a México en la expedición de 1580 ; murió...; sábese de su existencia por cita que de él hace el P. General Everardo Mercuriano.

3 Albizuri, Martín.-H.-Nació en Azcoitia, Vasconia, 1552; entró en la Cía. en México, 1573; fué expulsado.

4 Albornoz, Bernardino.-P.-Nació en México; entró en la Cía. en México, 1573; murió en 1615, en dicha ciudad.

5 Albornoz, Bernardino.-H.-Wació en Guadalajara, España, 15 52; entró en la Cía. en Alcalá, 1570; pasó a México en la expedición de 1574; murió en 1579 .

6 Alcázar, Juan de.-H.-Nació en México, 1560; entró en la Cía. en México, 1587; murió en México, 1623.

7 Aldana, Juan de.-H.-Nació en Antequera, Andalucía, 1563; entró en la Cía. en 1589; pasó a México antes de terminar el siglo con el P. Antonio de Mendoza; murió en México, 1625. 
8 Aldricio, Juan Bautista.-H.-Nació en la Diócesis de Sena, 1544; entró en la Cía. en Roma, 1567; pasó a México en la expedición de 1577; murió en México en 1615.

9 Almerique, Francisco.-P.-Nació en Pesaro, Italia, 1555.Entró en la Cía. en 1575; pasó a México en la expedición de 1580; murió en misiones, en 1601 .

10 Alvarez, Juan.-P.-Nació en ... ; entró en la Cía. en ... ; pasó a México en ...; murió en Puebla, 1623. (Citado por Pérez de Rivas y Florencia.)

11 Alvarez, Salvador.-H.-Nació en Plasencia, 1549; entró en la Cía. en México; murió en México, 1590.

12 Andrés, Juan.-H.- - Nació en Tordesillas, 1548; entró en la Cía. en 1577; pasó a México en la segunda expedición de 1579; murió en Guadalajara; fué Coadjutor temporal formado en México el 24 de septiembre de 1589 .

13 Angel, Cristóbal.-P.-Nació en San Clemente, Cuenca, 1552; entró en la Cía. en Alcalá, 1573; pasó a México en la expedición de 1580 ; murió en 1632 .

14 Aranguren, Francisco de.-P.-Nació en México... ; entró en la Cía. en México (?), 1577; fué expulsado.

15 Arbano, Mateo.-H.-Nació en ...; Coadjutor temporal formado en México, febrero 24 de 1595.

16 Arias, Antonio.-P.-Nació en 1570; entró en la Cía. en ...; pasó a México en 1600; murió en México, 1603.

17 Arnaya, Nicolás de.-P.-Nació en Segovia, 1558; entró en la Cía. en Alcalá, 1575; pasó a México en 1584, con el P. Antonio de Mendoza; murió en México, 1623.

18 Arriaga, Alonso.-H.-Nació en México...; entró en la Cía. en México (?), 1578; fué expulsado.

19 Arriaga, Antonio.-Escolar.-Nació en México...; i entró en la Cía. en México (?), 1579; fué expulsado.

20 Avellaneda, Diego de.-P.-Nació...; entró en la Cía. en ...; pasó a México como Visitador en 1590; fué removido al Perú, 1599.

21 Avendaño, Cosme.-P.-Nació en México, 1561 ; entró en la Cía. en México, 1579; murió en San Gregorio de México (?), 1623.

22 Barrera, Gil.-Escolar.-Nació en Fregenal; entró en la Cía. en 1579; fué expulsado. 
23 Bazán, Francisco.-P.-Nació en Guádix; entró en la Cía. en 1558 , en Castilla; pasó a México en 1572, como fundador; murió en México, 1572.

24 Beltrán, Vicente.-H.-Nació én 1546; entró en la Cía. en Roma, 1569; pasó a México con el $P$. Antonio de Mendoza, 1584; murió en México, 1625.

25 Berrusello,...-P.-Nació... ; entró en la Cía. en 1576; fué expulsado.

26 Blanco, Juan.-H.-Nació en Villaviciosa, 1572; entró en la Cía. en México, 1591; murió en Puebla, 1625.

27 Bravo, Cristóbal.-P.-Nació... ; entró en la Cía. en Alcalá, 1577; pasó a México en ... ; murió en México en 1609.

28 Cabiato, o Cabrato, José--P.-Nació en Milán; entró en la Cía. en ...; pasó a México en ...; murió en México, 1595.

29 Cabrera, Cristóbal de.-P.-Nació en México, 1553; entró en la Cía. en México, 1573; murió en 1590.

30 Cabrera, Francisco.-Escolar.-Nació en Oaxaca; entró en la Cía. en México (?), 1579; fué expulsado.

31 Camargo, Alonso.-P.-Nació en Guadalajara, España; entró en la Cía. en ... ; pasó a México en 1572, como fundador; murió en México, 1619.

32 Cano, Agustín.-P.-Nació...; entró en la Cía. en México; murió en 1622, México. (Citado por Pérez de Rivas y Florencia.)

33 Carmona, Juan de.-Escolar.-Nació en Puebla ... ; entró en la Cía. en México (?), 1581 ; fué expulsado.

34 Carrera, Juan de la.-H.-Nació en Bembribe, Astorga; entró en la Cía. en Burgos, junio 12 de 1555; llegó a México en 1574; murió en Puebla, 1601.

35 Carriedo, Andrés.-P.-Nació en Quintanilla de San García, Burgos, 1541 ; entró en la Cía. en 1565 ; pasó a Méxica en la expedición de 1579; murió en México, 1594.

36 Carvajal, Gaspar de.-P.-Nació en México, 1562; entró en la Cía. en México, 1586; murió en Puebla, 1647.

37 Castañera, Pedro.-P.-Nació en San Martín, Lugo; entró en la Cía. en México, 1573; murió en México, 1603.

38 Castro, Francisco de.-H.-Nació en ...; Coadjutor temporal formado en México, mayo 5 de 1596. 
39 Castro, Ildefonso de.-P.-Nació en Toledo; entró en la Cía. en ... ; pasó a México y fué Provincial de 1600 a 1608.

40 Cervantes, Baltasar de.-P.-Nació en Oaxaca, 1579; entró en la Cía. en México, 1594 ; murió en México, 1649.

41 Ciguerondo, Juan.-P.-Nació en Cádiz; entró en la Cía. en México, 1576; murió...

42 Contreras, Francisco de.-P.-Murió en Oaxaca. (Citado por Pérez de Rivas.)

43 Covarrubias, Luis.-P.-Nació en Constantina, Sevilla; entró en la Cía. en México, 1579; murió en México, 1626.

44 Crox o Croz, Juan.-H.-Nació en 1551; entró en la Cía. en Aragón; murió en Puebla, 1614.

45 Curiel, Juan.-H.-Nació en Aranda de Duero; entró en la Cía. en ... ; pasó a México en 1572, como fundador; murió en Pátzcuaro, 1576.

46 Chioti, Teófilo.-H.-Nació ... ; entró en la Cía. en Roma; pasó a México ...; murió en México, 1594.

47 Dávalos, Juan.-P.-(Citado por Pérez de Rivas.)

48 Díaz de Pangua, Diego.-P.- Nació en San Martín, Nueva Vizcaya, 1572; entró en la Cía. en México, 1590; murió en México, 1631.

49 Diaz, Gabriel.-P.-Nació en Tarora, 1574; entró en la Cía. en Portugal, 1591; pasó a México en 1599; murió en México, 1648.

so Díaz, Juan.-P.-Nació en Jerez de la Frontera, 1544; entró en la Cía. en 1567; pasó a México en la expedición de 1579; murió...

51 Díaz, Pedro.-P.-Nació en Orchi, Alcarria, o en Lupiana (?), 1545; entró en la Cía. en Alcalá, 1565; pasó a México en 1572, como fundador; murió en 1618, o 1619, en México.

52 Durán Loaisa, Juan.-P.-Nació en Toledo, 1553; entró en la Cía. en 1571; pasó a México en la expedición de 1579; murió en México en 1597, o 1598, en la casa Profesa.

53 Echavarría, Hernando de.-H.-Coadjutor temporal formado en México, el 11 de octubre de 1592.

54 Egurrola, Pedro.-P.-Nació en México, 1585; entró en la Cía. en 1600; murió en Malinalco, 1637.

55 Escorza, Lorenzo.-H.-Nació en Motrico, Vasconia, 1545; entró en la Cía. en México, 1573; fué expulsado antes de 1592. 
56 Espínola, Juan Bautista.-P.-Nació en Sevilla, 1549; entró en la Cía. en México, 1573; murió en México, 1619.

57 Espinosa, Juan Bautista de.-H.-Nació en España, 1534; entró en la Cía. en México, 1594; murió en Valladolid, Michoacán, 1624.

58 Farfán, Jerónimo.-H.-Nació en Palencia; entró en la Cía. en 1579; fué expulsado.

59 Fernández de Segura, Alonso.-P.-Nació en Segura, 1525; entró en la Cía. en México, 1573; murió en Puebla, 1588.

60 Fernández, Juan.-P.-Nació en Montilla, 1544; entró en la Cía. en Sevilla, 1566; pasó a México en la expedición de 1577; murió en Oaxaca, 1577 .

61 Fernández, Martín.-P.-Nació en Daimiel, 1551; entró en la Cía. en Alcalá, 1569; pasó a México en la expedición de 1579; murió en México, 1619.

62 Ferro, Juan.-P.-Nació en Sicilia, 1543; entró en la Cía... en 1569; pasó a México en la expedición de 1578; murió en Pátzcuaro, 1617.

63 Gallardo, Nicolás.-H.-Nació en Alcalá, 1554; entró en la Cía. en 1570; pasó a México en la expedición de 1580; murió en 1614, en México.

64 Gallego, Pablo.-H.-Nació en ... ; entró en la Cía. en 1579; fué expulsado.

65 Gallo, Juan Rafael.-Escolar.-Nació en México; entró en la Cía. en México (?), 1576; fué expulsado.

66 García, Diego.-P.-Nació en Barlanas, Avila, 1552; entró en 1a Cía. en 1572; pasó a México en la segunda expedición de 1579; murió en Manila, 1604.

67 García, Francisco.-H.-Coadjutor temporal formado en México, marzo 28 de 1595 .

68 García, Marcos.-H.-Nació en Toledo, 1550 ó 1552; entró en la Cía. en 1573; pasó a México en la expedición de 1576; murió en Puebla, 1620 .

69 Gómez, Cristóbal.-P.-Nació en Fregenal, 1561; entró en la Cía. en Andalucía, 1592; pasó a México en 1595; murió en México, 1638.

70 Gómez de Cervantes, Alonso.-P.-Nació en México, 1578; entró en la Cía. en México, 1598; murió en México, 1634. 
71 Gómez, Esteban.-H.-Nació en Tenerife, 1550; entró en la Cía. en México, 1578; murió...

72 Gómez, Gaspar.-H.-Nació en Ocaña; entró en la Cía. en Alcalá, 1573; pasó a México en la expedición de 1580; murió, según parece, en España.

73 Gómez, Juan.-H.-Nació en Vizcaya; entró en la Cía. en 1579; fué expulsado.

74 González, Andrés.-H.-Nació en Italia (?); entró en la Cía. en ... ; pasó a México en la expedición de 1580; pero murió en el mar, antes de llegar a su destino. Lo pongo aquí por parecerme que virtualmente formó parte de la Provincia.

75 González, Francisco.-H.-Entró en la Cía. en 1574; fué expulsado.

76 González Infante, Diego.-P.-Nació en Atlixco, 1564; entró en la Cía. en México, 1594; murió en Puebla, 1644.

77 González, Martín.-H.-Nació en Toledo, 1548; otros dicen que en Pasarón, diócesis de Plasencia; entró en la Cía. en Alcalá; pasó a México en 1572, como fundador; murió en México, 1600.

78 Guillén, Alonso.-P.-Nació en Gibraltar, 1546; entró en la Cía. en Salamanca, 1566; pasó a México en la expedición de 1576; murió en Oropesa, 1594.

79 Gutiérrez, Francisco.-P.-Nació en Guadalajara; entró en la Cía. en 1580; fué expulsado.

80 Gutiérrez, Pedro.-P.-Nació en el mar, camino de Nueva España, 1554; entró en la Cía. en México, 1576; murió en 1633, en México.

81 Hernández, Andrés.-H.-Nació en Maderal; entró en la Cía. en 1576; fué expulsado.

82 Hernández, Martín.-P.-Nació en Daimiel, Toledo, 1548 ; entró en la Cía. en 1569; pasó a México en la expedición de 1579; murió en Tepotzotlán, 1620.

83 Hernández, Pedro.-H.-Coadjutor temporal formado en México el 18 de octubre de 1599.

84 Hernández Ovanes, Pedro.-H.-Coadjutor temporal formado en México el 24 de febrero de 1595.

85 Herrera, Diego.-P.-Nació en Villalón, 1546; entró en la Cía. en Salamanca, 1568; pasó a México en la expedición de 1576; murió en México, 1595. 
86 Illescas, Juan.-H.-Nació en Oaxaca; entró en la Cía. en 1579; fué expulsado.

87 Illescas, Mateo.-P.-Nació en Oaxaca; entró en la Cía. en 1579; fué expulsado. (¿Será el mismo que el anterior?)

88 Isla, Diego de.-H.-Nació en Sevilla, 1545; entró en la Cía. en México; murió antes de 1582. (Era carpintero.)

89 Juárez, Alejandro.-H.-(Citado por Pérez de Rivas.)

90 Lanuchi, Vicente.-P.-Nació en Italia, 1543; entró en la Cía. en Mesina, 1559; pasó a México como Superior de la expedición de 1574. Fué devuelto a España.

91 Larios, Bartolomé.-H.-Nació en Castilla; otros dicen que en Cuenca de Campos, León, en 1535 ; entró en la Cía. en Medina del Campo, 1554; pasó a México en 1572, como fundador; murió en...

92 Laurencio, Juan.-P.-Nació en Paraquellos, 1561; entró en la Cía. en Toledo; pasó a México en ... ; murió en México en 1633.

93 Loaisa, Alonso.-H.-Nació en ...; entró en la Cía. en 1581; fué expulsado.

94 Logroño, Gabriel de.-P.-Nació en Málaga, 1531; entró en la Cía. en México, 1574; murió en 1612, en México.

95 López de Arvaisa, Juan.-H.-Nació en Durango, España, 1556; entró en la Cía. en la Provincia de Castilla, 1574; pasó a México en 1588; murió en México, 1612.

96 López de la Parra, Pedro.-P.-Nació en Salamanca, 1546; entró en la Cía....; pasó a México en 1572, como fundador; murió en 1602, ahogado, en viaje de Filipinas a México.

97 López de Lorca, ...-H.-Nació en Puebla; entró en la Cía. en 1581; fué expulsado.

98 López de los Hinojosos, Alonso.-H.- Nació en el pueblo de los Hinojosos, Cuenca; entró en la Cía. en México, 1585; murió en México en $1596,01597$.

99 López de Mesa, Diego.-P.-Nació en Cafra, Castilla; entró en la Cía. en ... ; pasó a México en 1572, como fundador; murió en México, 1615 .

100 López Fonseca, Diego.-P.-Nació en Castro Mocho, 1531; entró en la Cía. en Salamanca; pasó a México en 1572, como fundador; murió en México, 1576. 
101 López, Jerónimo.-H.-Nació en Sevilla; entró en la Cía. en México, 1578; murió en Guadalajara de México, 1596.

102 López, Pedro.-H.-Nació en Oaxaca (?) ; entró en la Cía. en México, 1586; murió en Oaxaca, 1614.

103 Llanos, Bernardino de.-P.-Nació en Ocaña, 1556; entró en la Cía. en Salamanca, 1580 ; pasó a México antes de expirar el siglo, con el P. Antonio de Mendoza, 1584 (?) y murió en México en 1639.

104 Majano, Francisco.-P.-Nació en Toledo, 1541; entró en la Cáa. en Toledo, 1570; pasó a México en la expedición de 1580; murió en México, 1619.

105 Mantilla, Martín de.-H.-Nació en Aragón; otros dicen que en Villaverde de Salamanca, 1543; entró en la Cía. en Valencia, 1564; pasó a México en 1572, como fundador; murió en México, 1597.

106 Marco (el Hermano).-Nació...; entró en la Cía. en ...; pasó a México en la $2^{2}$ expedición de 1579; murió en Barcelona, 1581, acompañando al Procurador P. Francisco Báez.

107 Márquez, Melchor.-P.-Nació en México, 1564; entró en la Cía. en México, 1579; murió en 1637, en México.

108 Marquina, Antonio.-H.-Nació...; entró en la Cía. en ...; pasó a México, en la expedición de 1574; murió en 1575.

109 Martín, Alonso.-H.-Entró en la Cía. en 1575; fué expulsado.

110 Martín, Bartolomé--H.-Coadjutor temporal formado en México, el 24 de agosto de 1599.

111 Martín, Benito.-H.-Coadjutor temporal formado en México, el 11 de junio de 1600.

112 Mejía Cogollos, Pedro.-P.-Nació en Guadalajara, España, 1551, o en 1557; entró en la Cía. en Alcalá, 1569; pasó a México en la expedición de 1577; fué expulsado.

113 Méndez, Lope.-H.-Nació en Badajoz; entró en la Cía. en . . . ; fué expulsado.

114 Méndez, Pedro.-P.-Nació en Villaviciosa, 1555; entró en la Cía. en Roma, 1573; pasó a México antes de 1583; murió en México en 1643 .

115 Mendoza, Antonio de.-P.-No sé dónde nació. Fué Provincial en México de 1585 a 1590. 
116 Mendoza, Juan de.-P.-Nació en la Isla de Santo Domingo, 1543 ; entró en la Cía. en Sevilla, 1563 ; pasó a México en la expedición de 1576; murió en Puebla, 1595.

117 Meneses, Gaspar de.-P.-Nació en Puebla, 1563; entró en la Cía. en la Provincia de Castilla, 1598; pasó a México con el P. Ortigosa; murió en México en 1631.

118 Mercado, Pedro.-H.-Nació en México, 1546; entró en la Cía. en Sevilla, 1566; pasó a México en 1572, como fundador; murió en México, 1619.

119 Merino, Juan.-H.-Nació en Molina de Aragón, 1551; entró en la Cía. en Alcalá, 1570; pasó a México en la expedición de 1574; murió en México, 1580. Otros dicen que en Pátzcuaro, 1577.

120 Montemayor, Hernando.-P.-Coadjutor Espiritual formado en México el 22 de julio de 1591.

121 Montes, Gregorio.-H.-Nació en Alcalá, 1540; entró en la Cía. en Córdoba, 1565; pasó a México en la expedición de 1576; murió en Pátzcuaro, 1611. Fué Coadjutor temporal formado en México el 25 de marzo de 1588 .

122 Mora, Sebastián de.-Entró en la Cía. en 1578; fué expulsado.

123 Morales, Pedro de.-P.-Nació en Valdepeñas, 1538; entró en la Cía. en Alcalá (?); pasó a México en la expedición de 1576; murió en México el 6 de septiembre de 1614.

124 Moro, Gaspar.-H.-Nació en Valladolid, 1557; entró en la Cía. en 1572; pasó a México en la expedición de 1579; volvió a España.

125 Navarro, Lope.-H.-Nació en Toledo; otros dicen que en Navarra; estaba en Toledo cuando pasó a México en 1572, como fundador; regresó a España.

126 Nieto, Pedro.-H.-Nació en Asturias, 1505; entró en la Cía. en México, en 1583; murió en México, en 1637, a los 132 años de edad.

127 Ortega, Juan de.-Escolar.-Nació en Michoacán; entró en la Cía. en 1580; fué expulsado.

128 Ortigosa, Pedro.-P.--Nació en Ocaña, 1546; entró en la Cía. en 1564 ; pasó a México en la expedición de 1576; murió en México, 1626.

129 Ortiz de Rivera, Pedro.-Escolar.-Nació en Sombrerete; entró en la Cía, en 1581; fué expulsado.

130 Ortiz, Millán.-P.-Nació en Tasco; entró en la Cía. en 1578; fué expulsado. 
131 Ovalle, Pedro de--H.-Coadjutor temporal formado en México el 23 de febrero de 1598.

132 Pacheco, García.-P.-Coadjutor Espiritual formado en México el 25 de diciembre de 1587.

133 Páez, Esteban.-P.-Pasó a México en 1590, y de 1594 a 1599 fué Provincial. Fué removido al Perú.

134 Palma, Hernando.-H.-Nació en Ecija, 1539 ; entró en la Cía. en 1563; pasó a México en la expedición de 1576; murió en Oaxaca, 1614. Fué Coadjutor temporal formado en México el 14 de mayo de 1587.

135 Pérez, Alonso.-H.-Nació en Cádiz, 1538; entró en la Cía. en Roma, 1562; pasó a México en la expedición de 1576; murió en México en 1602 .

136 Pérez de Andosilla, Juan.-H.-Nació en Andosilla, 1540; Coadjutor temporal formado en México el 4 de noviembre de 1584; murió en 1604.

137 Pérez de Landesa, ...-H.-Nació en Bermeo, Vizcaya; entró en la Cía. en México, 1575; murió en 1580.

138 Pérez, Juan.-P.-(Citado por Pérez de Rivas.)

139 Perusino, Domingo.-H.-Nació en Perusa, 1560; entró en la Cía. en 1578; pasó a México en la expedición de 1580; murió en México en 1611 .

140 Plaza, Juan de la.-P.-Nació en Medinaceli, 1528; entró en la Cía. en Alcalá, 1553; pasó a México en la $2^{3}$ expedición de 1579, como superior; murió en México, 1602.

141 Prat, o Prado, Raimundo, o Ramón.-P.-Nació en Barcelona, 1556; entró en la Cía. en 1577; pasó a México en la expedición de 1579; murió en Manila, 1605 .

142 Puente, Martín de la.-H.-Coadjutor temporal formado en México el 30 de noviembre de 1586 .

143 Quiroz, Agustín de.-P.-Nació en Andújar, Andalucía, 1566; entró en la Cía. en 1581; pasó a México en 1600 (?); murió en México, 1622.

144 Rama, Francisco.-H.-Nació . . . ; entró en la Cía. en ... ; pasó a México en la expedición de 1577; murió antes de 1580, en México.

145 Ramírez, Francisco.-P.-Nació en León, España, 1553; entró en la Cía. en 1570; pasó a México en la expedición de 1579; murió en 1630, en México. 
146 Ramírez, Jerónimo.-P.-Nació en Sevilla; entró en la Cía. en México, 1578 ; murió en Pátzcuaro, 1621.

147 Ramos, (el Hermano).-Llegó a México en 1574, en la expedición encabezada por el P. Lanuchi. (Citado por el Anónimo de la Relación Breve, 1602.)

148 Rana, Hernando.-Escolar.-Nació en Puebla; entró en la Cía. en 1581; fué expulsado.

149 Rentería, Ignacio.-Escolar.-Nació en Zacatecas; entró en la Cía. en 1576; fué expulsado.

150 Rico, o Rizo, Estcban.-H.-Nació en Cádiz, 1550; entró en la Cía. en Sevilla, el 25 de dic. de 1567; pasó a México en la expedición de 1574; murió en 1635, en México (?).-Fué Coadjutor temporal formado en México el 6 de enero de 1585 .

151 Rincón, Antonio del.-P.-Nació en Puebla, 1556; entró en la Cía. en México, 1573; murió en misión, cerca de Puebla, en 1600.

152 Ríos, Ambrosio de los.-P.-Nació en Navarra; entró en la Cía. en ...; pasó a México en 1597 (?); murió en México en 1637.

153 Rivas, Miguel de.-P.-Nació en Valencia, 1545; entró en la Cía....; pasó a México en 1599 (?); murió en Michoacán, 1638.

154 Rodríguez, Nicolás.-Escolar.-Nació en Sevilla; entró en la Cía. en 1581; fué expulsado.

155 Rodríguez, Pedro.-P.- Nació en Arévalo; entró en la Cía. en Sevilla, 1568; murió en Oaxaca, 1604, habiendo llegado a México en la expedición de 1574 .

156 Rogel, Juan.-P.-Nació en Pamplona, 1528 ó 1529; entró en la Cía. en Valencia, el 15 de abril de 1554; pasó a México en 1574; murió en Veracruz, 1619.

157 Rojas, Martín de.-H.-Coadjutor temporal formado en México el 28 de octubre de 1589.

158 Rojas, Martín de.-H.- (otro, al parecer distinto del anterior) Coadjutor temporal formado en México el 15 de mayo de 1595.

159 Romero, Francisco.-H.-Nació en Triana, 1562; entró en la Cía. en México, 1579 ; murió en 1633.

160 Rubio, Antonio.-P.-Nació en Roda, Cuenca; entró en la Cía. en Alcalá, 1569; pasó a México en la expedición de 1576; murió en Madrid, 1615 .

161 Ruiz, Alonso.-P.-Nació en Sevilla, 1538; entró en la Cía, en 1554; pasó a México en la expedición de 1576; murió en Veracruz, 1612. 
162 Ruiz, Bartolomé.-H.-Nació en Santa Firma, Córdoba, 1543; entró en la Cía. en México, en 1577; murió en México en 1619. (Era sastre.)

163 Ruiz de Salvatierra, Pedro.-H.-Nació en Salamanca, 1542; entró en la Cía. en la Habana, 1570 (?); pasó a México en 1576; murió...

164 Ruiz, Pedro.-H.-Coadjutor temporal formado en México el 11 de diciembre de 1584 .

165 Salamanca, Martín de.-P.-Nació en Zacatecas; entró en la Cía. en México (?), 1581 ; fué expulsado.

166 Salcedo, Juan de.-H.-Nació en Trucios, Burgos, 1543 ; entró en la Cía. en ... ; pasó con el P. Sedeño a México, en 1572; murió en Valladolid, España, 1598.

167 Saldaña, Bartolomé.-P.- - Nació en Sevilla, 1510 ; entró en la Cía. en México, 1573; murió en 1581, en México (?).

168 Salgado, Gonzalo.-H.-Coadjutor temporal formado en México, el 15 de mayo de 1595 .

169 Sánchez, Alonso.-P.-Nació en Mondéjar, 1535; entró en la Cía. en 1564; pasó a México en la expedición de 1579; volvió a España y murió en Alcalá, 1593.

170 Sánchez Baquero, Juan.-P.-Nació en Puerto Llano, Andalucía, 1547; entró en la Cía. en Alcalá, 1569; pasó a México en 1572, como fundador, siendo aún Hermano; murió en Oaxaca, 1619.

171 Sánchez, Francisco.-H.-Nació en Castilla; entró en la Cía. en 1574; volvió a España y fué expulsado en 1593.

172 Sánchez, Francisco.-P.-Nació...; entró en la Cía. en Alcalá, 1569; pasó a México en la expedición de 1574; fué expulsado en 1593.

173 Sánchez, Pedro.-P.-Nació en San Martín, Toledo, 1528; entró en la Cía. en Alcalá, 1558; pasó a México en 1572, como fundador; murió en México, 1609.

174 Sánchez, Pedro.-H.-Coadjutor temporal formado en México el 8 de diciembre de 1592 .

175 Sandoval, Manuel.-P.-Nació en México, 1575 ; entró en la Cía. en México, 1591; murió en 1613.

176 Santiago, Alonso.-P.-Nació en Tasco, 1554; entró en la Cía. en México, 1573; murió en Oaxaca, 1604.

177 Santiesteban, Diego de.-P.-Nació en la Villa de Palma, Andalucía, 1564; entró en la Cía. en 1581, en Andalucía; pasó a México en 1584; murió en México, 1637. 
178 Santos, Bartolomé-H.-Nació en Villada, León; entró en la Cía. en 1579; murió en México en 1610. No sé cuándo pasó a la Nueva España, pero supongo fué antes de terminar el siglo xvi.

179 Sedeño, Antonio.-P.-Nació en San Clemente; entró en la Cía. en Loreto, 1559; pasó a México en junio de 1572 a preparar el arribo de la misión fundadora; murió en Cebú, Filipinas, 1595.

180 Simón, Francisco.-H.-Nació en Ciudad Rodrigo, 1559; entró en la Cía. en 1590; pasó a México en ...; murió en México en 1596.

181 Suárez, Diego.-P.-Nació en Evora, Portugal, 1543; entró en la Cía. en Sevilla, 1563; pasó a México en la expedición de 1577; fué expulsado.

182 Suárez de la Concha, Hernando.-P.-Nació en Medina del Campo, 1527 ; entró en la Cía. en la Provincia de Castilla, 1558; pasó a México en 1572, como fundador; murió en México en 1607.

183 Suárez de Toledo, Gaspar--H.-Nació en Granada, 1554; entró en la Cía. en 1573; pasó a México en la expedición de 1579; murió en el mar, viaje a Filipinas, en 1581.

184 Suárez, Hernán.-P.-Nació en Granada, 1543; entró en la Cía. en 1568; pasó a México como superior de la expedición de 1578; murió en Laguio, Filipinas, en 1586.

185 Tapia, Gonzalo de.-P.-Nació en León, Castilla; entró en la Cia. en...; pasó a México en ... ; murió en el pueblo de Daropa, Sinaloa, a manos de los bárbaros, el 11 de julio de 1594 .

186 Tello, Francisco.-H.-Entró en la Cía. en 1578; fué expulsado.

187 Tercero, Francisco.-H.-Nació en Villarrobledo, Toledo, 1551; entró en la Cía. en 1573; pasó a México en la expedición de 1579; murió en la Puebla, 1579.

188 Tomé, Pedro.-P.-Nació en ...; pasó a México en la expedición del P. Pedro Díaz; murió en México, 1608.

189 Torres, Antonio.-P.-Nació en Gumiel, 1535 ; entró en la Cía. en 1556; pasó a México como Superior de la expedición de 1579; volvió a España.

190 Torres, Diego de.-H.-Nació en Valladolid, 1557; entró en la Cía. en 1576; pasó a México en la expedición de 1579; murió en Tepotzotlán, 1633.

191 Torres, Luis.-H.-Entró en la Cía. en 1580; fué expulsado.

192 Tovar, Juan de.-P.-Nació en México, 1541; entró en la Cía. en México, 1573; murió en el Colegio de México, 1626. 
193 Trujillo, Diego.-Nació en Madrilejo, 1539; entró en la Cía. en México, 1576; murió en México, 1580.

194 Urrutia, Juan de.-H.-Nació en Villafranca, Navarra, 1540; entró en la Cía. en México, 1574; murió en México, 1610; Coadjutor temporal formado en México el 30 de noviembre de 1586. Otros dicen nació en 1548, habiendo sido recibido en 1576 .

195 Váez, Francisco.-P.-Nació en Segovia, 1543 ó 1544; entró en la Cía. en Salamanca, 1566; pasó a México como Superior de la expedición de 1576; murió en 1619, en México.

196 Valdepeñas, Baltasar de.-H.-Nació en Sevilla; entró en la Cía. en 1581; fué expulsado.

197 Vázquez, Hernán.-H.-Nació en México, 1556; entró eti la Cía. en 1571, en Alcalá; regresó a México en la expedición de 1579; murió en Puebla, 1592.

198 Vega, Cristóbal de la.-H.-Nació en Granada, 1556; entró en la Cía. en México, 1574; murió en México antes de 1582. (Era albañil.)

199 Velasco, Miguel.-H.-Entró en la Cía. en 1580; fué expulsado.

200 Vidal, Pedro.-H.-Nació en Cañada, Tarragona, 1555; entró en la Cía. en 1576; pasó a México en la expedición de 1579; murió en Tepotzotlán, 1622 .

201 Villalta, Carlos.-P.-Nació en 1520, México; entró en la Cía. en México, 1580; murió en México, 1594.

202 Villarreal, Francisco.-H.-Nació en Madrilejos, 1530; pasó a México en 1574, habiendo entrado en la Cía. en Montilla, 1559; fué formado Coadjutor temporal en México, el 6 de enero de 1585, y murió en dicha ciudad el 18 de enero de 1600 .

203 Villegas, Diego.-P.-Nació en México; entró en la Cía. en esta ciudad, 1581; murió en Guadalajara, 1598.

204 Vitoria, Juan de.-P.-Coadjutor Espiritual formado en México el 8 de septiembre de 1586 .

205 Zarfate, Francisco.-P.-Nació en México; entró en la Cía. en México, 1581; murió en misiones (?) en 1597.

206 Zarfate, Pedro.-P.-Entró en la Cía. en 1577; fué expulsado. Había nacido en México.

207 Zayas, Marcos de,-H.-Nació en México; entró en la Cía. en 1577; fué expulsado. 


\section{ADICIONES AL APENDICE}

1 Benítez, Andrés.-H.-(Citado por el Anónimo de la Relación Breve, 1602.)

2 Crespo, Juan.-H.-(Citado por el Anónimo de la Relación Breve, 1602.)

3 Figueroa, Juan de.-H.-(Citado por el Anónimo de la Relación Breve, 1602.)

4 Gallegos, Miguel.-H.-(Citado por el Anónimo de la Relación Breve, 1602.)

5 Gómez, Hernán.-P.-Nació en México (?); entró en la Cía. en México, 1573; murió en San Luis de la Paz (?), 1610.

6 Jabera, (el Hermano).-H.- (Citado por el Anónimo de la Relación Breve, 1602.)

7 Medrano, Alonso de.-P.-(Citado por el Anónimo de la Relación Breve, 1602.)

8 Ovalle, Alonso.-H.-(Citado por el Anónimo de la Relación Breve, 1602.)

9 Peláez, Martín.-P.-Nació... En 1595 estaba en Nueva España. Acompañó a don Alonso Díaz, vecino de Guadiana, a reprimir una rebelión en Sinaloa. De mayo de 1608 a marzo de 1609 fué Provincial. Fué Rector del Colegio de Puebla y del de México.

10 Salvador, (el Hermano).-H.- (Citado por el Anónimo de la Relación Breve, 1602.) 
